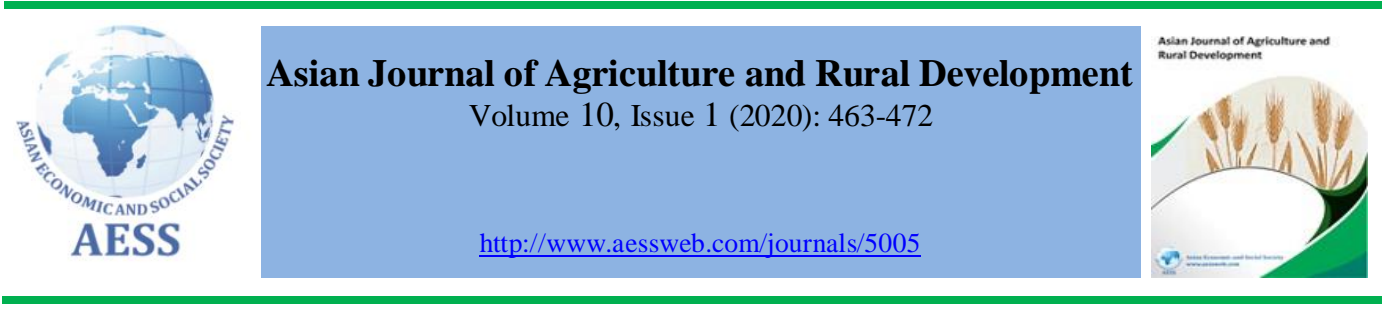

\title{
ESTIMATING THE CRITERIA AFFECTED TO AGRICULTURAL PRODUCTION: CASE OF CHAU THANH A DISTRICT, VIETNAM
}

\author{
Pham Thanh $V \mathbf{u}^{\mathrm{a}}$, College of Environment and Natural Resources, Can \\ Vo Quang Minh ${ }^{\mathrm{a}}$, Tho University, Vietnam \\ Phan Chi Nguyen ${ }^{\mathrm{a}}$, \\ Tran Van Dung ${ }^{\mathrm{b}}, \quad{ }^{\mathrm{b}}$ College of Agricultural, Can Tho University, Vietnam \\ Nguyen The Cuong c, c Mekong Delta Rice Research Institute, Vietnam \\ Nguyen Thi Phong \\ $\operatorname{Lan}^{\mathrm{c}}$

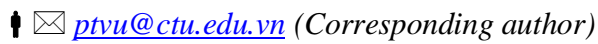

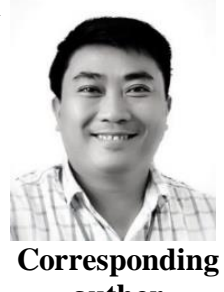

\section{ARTICLE HISTORY: \\ Received: 13-Mar-2020 \\ Accepted: 18-May-2020 \\ Online Available: 23 -Jun- \\ 2020}

Keywords:

Agricultural production, Analytical hierarchy process (AHP),

Criteria affecting,

Sustainable development, PRA

\begin{abstract}
The study aimed to assess the current agricultural production and to identify the criteria affecting the agricultural cultivation and overcome the limitations in agricultural production of Chau Thanh, A district of the Mekong Delta, Vietnam. The study collected primary from farmers using Participatory Rapid Appraisal tool, and discuss directly with experts and local agricultural managers. The results showed that economic development mainly based on agriculture (of which the paddy and fruit trees land were the most 13.577 ha $(98,8 \%))$. The five criteria were identified (techniques, physical, social, economic, and environment) and twenty-six sub-criteria, in which the production scale (0.084), infrastructure (0.071), total income (0.075) and profit (0.062) were the most important factors. The AHP analysis assisted in proposing several solutions such as infrastructure construction and non-structural solutions to cover the output of products to develop sustainable agricultural production. Therefore, the case study of Chau Thanh A district was used to support the development of agriculture production.
\end{abstract}

\section{Contribution/ Originality}

This study identified the important factors affected agricultural production. Based on these factors, we propose and prioritize the suitable solutions and recommendations for policy-makers to develop sustainable agricultural production in the future effectively.

DOI: 10.18488/journal.1005/2020.10.1/1005.1.463.472

ISSN (P): 2304-1455/ISSN (E):2224-4433

How to cite: Pham Thanh Vu, Vo Quang Minh, Phan Chi Nguyen, Tran Van Dung, Nguyen The Cuong and Nguyen Thi Phong Lan (2020). Estimating the criteria affected to agricultural production: case of Chau Thanh A district, Vietnam. Asian Journal of Agriculture and Rural Development, 10(1), 463-472.

(C) 2020 Asian Economic and Social Society. All rights reserved. 


\section{INTRODUCTION}

In recent years, natural conditions in the Mekong Delta in general and Chau Thanh A district, in particular, have been strongly influenced by the agricultural production activities of the farmer in the district as well as prolonged drought, erratic rainfall, unseasonal rain and flooding (Ha and Nguyen, 2016; Nguyen and Truong, 2014). In land use, the determination of natural, socioeconomic and environmental factors is also a factor affecting land use efficiency. The above issues pose challenges to managers, researchers, local authorities and communities in new research, rational models, adaptive solutions and policies for social balance and Economic output, environmental benefits this becomes urgent and complex. Especially, the physical conditions in the Mekong Delta are facing many challenges (Nguyen and Van, 2014). This is one of the areas most severely affected by climate change and sea-level rise (Smajgl et al., 2015). The physical conditions have also affected by the change in market prices (Phan et al., 2017, Du et al., 2018 and Viaggi et al., 2013) as well as soil degradation due to excessive use of pesticides (Nguyen and Do, 2015). The policy of restructuring agricultural sector of the district was aims to build the concentrated production areas (People's Committee of Hau Giang Province, 2016), at the same time re-evaluates the situation of agricultural production in recent years of the district, which has faced with rapid changes from specialized rice land to high economic value-added cropland (People's Committee of Chau Thanh A District, 2017). Therefore, agriculture is a very complex issue. To solve these issues, AHP is a useful method of decision-maker support. The Analytical Hierarchy Process (AHP) is a multi-criteria analysis method applied in many fields and suitable for many studies (Jacek, 1996; Thirumalaivasan et al., 2003; Gloria et al., 2007). The method, which enables the evaluation of group decisions with a specific systematic and logical approach, is used to choose the best alternative among the determined alternatives for a specific purpose to consider different criteria (Saaty and Peniwati, 2008; Saaty, 1980; Chiranjit and Kishore, 2016; Ali et al., 2019).

The study objective is to identify the current status of agricultural land use and the factors affecting agricultural production for the remedial proposal sustainable agricultural development, which improves the efficiency of land use and people's life in the district.

\section{MATERIALS AND METHODS}

\subsection{Data collection}

For analysis purpose, the data is collected by different means, details given below.

\subsubsection{Secondary data}

Available maps of land use of the study area in 2017 were collected at the Department of Natural Resources and Environment and the Department of Agriculture and Rural Development of the Chau Thanh A district, Hau Giang province. In addition, statistical - inventory data on land use, land use planning report and relevant physical, socio-economic data were collected according to the census data available at the Statistical Department and the People's Committee of the district. Such data were the main base to assess the land use current and affecting factors.

\subsubsection{Survey data}

A random survey of 70 farmers appropriately represent the whole population of the district was conducted to investigate the situation of agricultural production, criteria affecting the farming process and affected by agricultural production.

\subsubsection{Interview experts}

Forty-five experts (agricultural management officials, scientists and related organizations) were interviewed to identify the criteria and sub-criteria affecting agricultural production and impact level of each criteria. 
Detail of criteria and sub-criteria are shown in Table 1.

Table 1: The criteria and sub-criteria affecting agricultural production

\begin{tabular}{ll}
\hline Criteria (C1) & \multicolumn{1}{c}{ Sub-criteria (C2) } \\
\hline Techniques & Seasonal calendar, seed varieties, Tech-application, Type product, Fertilizer, \\
& Pesticides \\
Physical & Weather, Drought, Flood, Amount of rain \\
Economic & Income, Cost, Profit, Benefit/cost \\
Social & Policy, Labour, Capital, Knowledge, Infrastructure, Experts, Scale \\
Environment & Soil pollution, Water pollution, Salinization, Acidification, Disease \\
\hline
\end{tabular}

\subsubsection{Participatory rapid assessment method - PRA}

The research conducted 10 rural assessments at district administrative units to verify the collected data and to synthesize ideas from the producers directly as well.

\subsubsection{Multi-criteria valuation method}

This method was used to evaluate the impact of the criteria affecting agricultural production people in Chau Thanh A district, Hau Giang province. Hierarchical analysis in group decision making (AHP-GDM) (Saaty and Peniwati, 2008; Saaty, 1980) was used to limit the subjective bias of experts. The multi-criteria evaluation method was performed with 03 basic steps (Lu et al., 2007): (1) pair matching; (2) weighting; and (3) determine the consistency ratio (CR\%).

\subsubsection{Mapping method}

The method was used to synthesize and standardize the VN 2000 / WGS 84 zone 48 coordinate system (6 Degree), digitize, adjust, edit using Mapinfo software and create the thematic maps.

\section{RESULTS AND DISCUSSION}

\subsection{The current status of agricultural production of the study areas}

The actual situation of the study area until 2017 shown that the agricultural land area accounts for over $86 \%$ of the natural land area (People's Committee of Chau Thanh A district, 2017). This shown that Chau Thanh A district was a pure agricultural zone with diverse types of agricultural land use (Figure 1, 2).

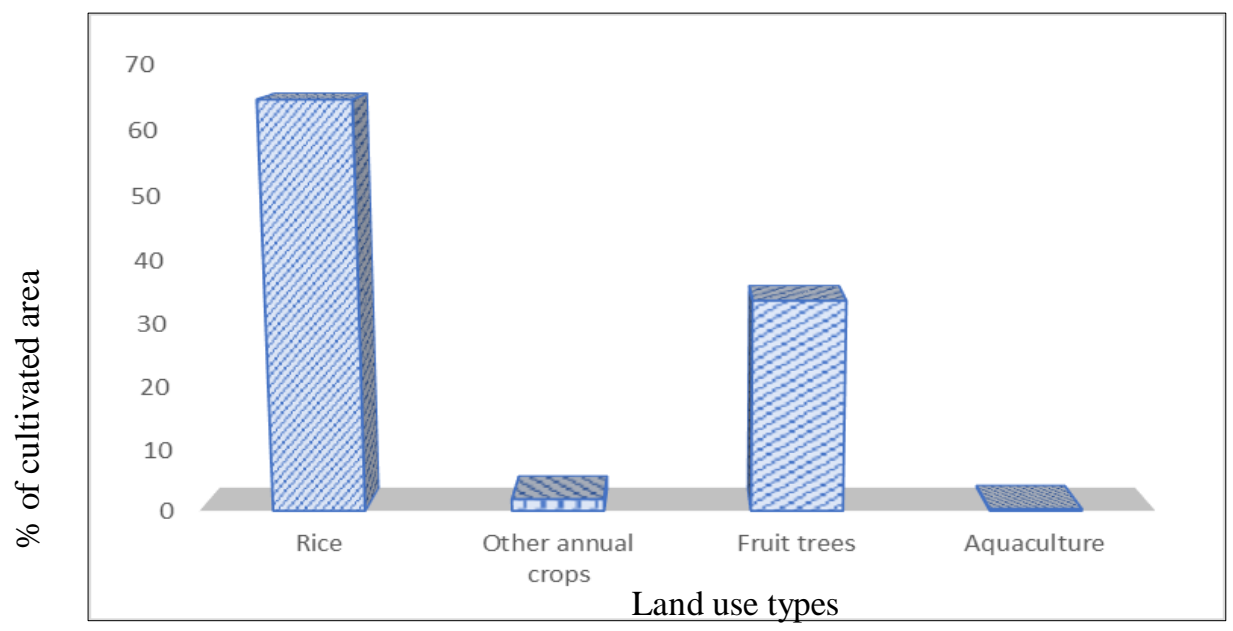

Figure 1: Uses of agricultural land in Chau Thanh A district in 2017

Source: Office of Agriculture and Rural Development of Chau Thanh A District, 2017 


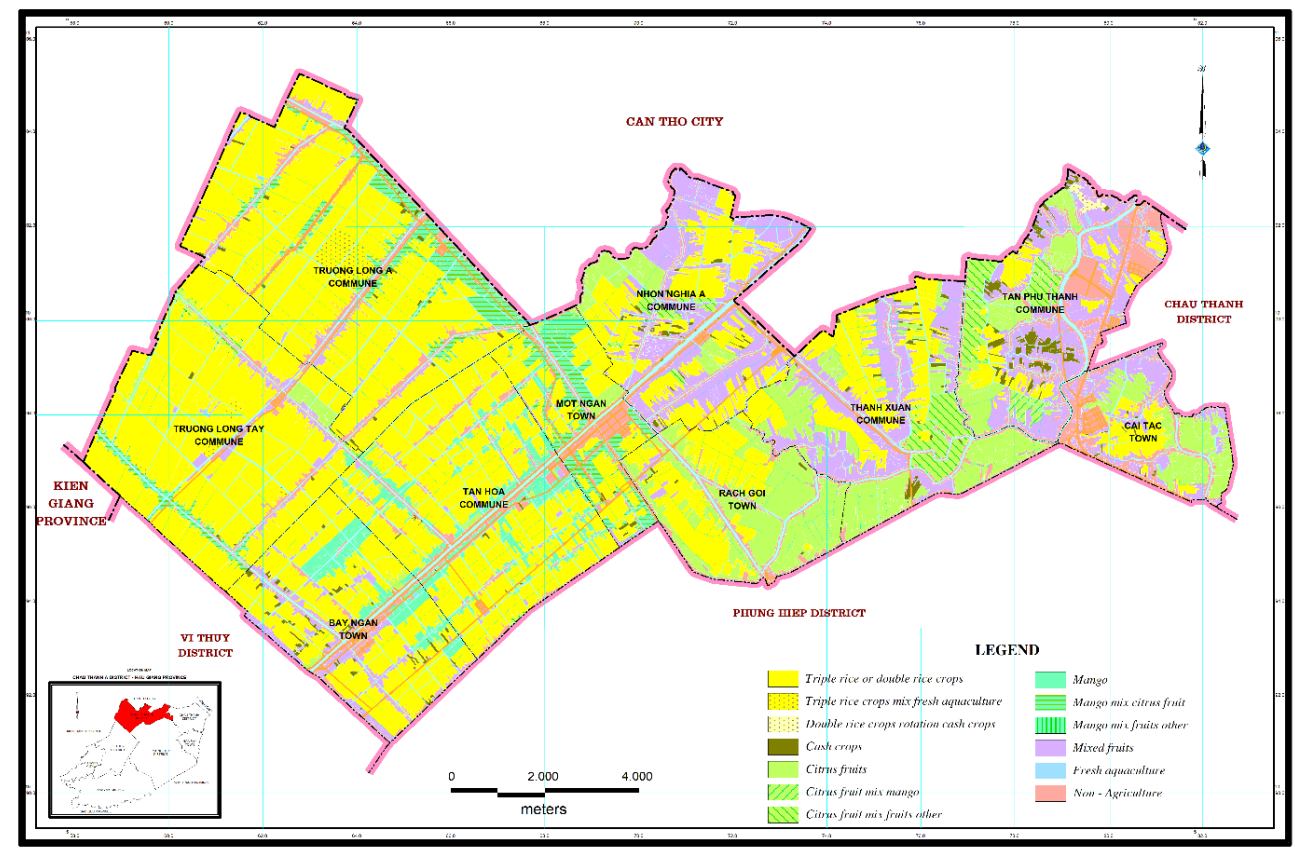

Figure 2: The current agricultural land use in Chau Thanh A district in 2017

According to the Land inventory statistics report (2017) and the field surveys showed that the agricultural farming status in Chau Thanh A district mainly consists of two main crops: rice and fruit trees with various types of land uses such as three rice crops, the combination of three rice crops and fish, double rice crops, rice - cash crops, cash crops and fruits (mainly salt-bearing crops such as oranges, grapefruit and lemon seedless and mango). However, in recent years, the area of fruit trees has grown massively and quickly on a small scale, which makes agricultural managers difficult to ensure planning due to the impact of market prices. Since, it made the difficulties in crop disease management and technology transfer, as well as the management of agricultural output and the quality of agricultural products.

\subsection{The criteria affecting agricultural production in the study area:}

The results of interviews with farmers, direct exchanges with experts as well as a rapid assessment of rural areas have identified five criteria (C1) affecting the agricultural production process of people in the study area, including physical, social-economic (Khoza et al., 2019), environment and farming techniques. According to experts shown the agricultural farming process in the district, the main influencing criteria is the social factor (weight 0.347) and followed by in the order of the physical (weight 0.188), economic (weight 0.165), environmental (weight 0.163), and techniques (weight 0.137), which were less impact on agricultural production (Table 2). The less impact of the technique on agriculture production is likely due to the district's traditional agriculture, long-term production experience, regular training in new techniques and application of new farming techniques in production. In recent years, the industrialization process has made the agricultural labour forces move to industrial zones which affecting agricultural production. 
Table 2: The weight of criteria and sub-criteria affecting agricultural production

\begin{tabular}{|c|c|c|c|c|}
\hline Criteria & $\begin{array}{c}\text { Weight of criteria } \\
\text { (W1) }\end{array}$ & Sub-criteria & $\begin{array}{c}\text { Weight of Sub-criteria } \\
\text { (W2) }\end{array}$ & $\begin{array}{c}\text { Total } \\
\text { weight } \\
\text { W=W1*W2 }\end{array}$ \\
\hline \multirow{6}{*}{ Techniques } & \multirow{6}{*}{0.137} & Seasonal calendar & 0.122 & 0.017 \\
\hline & & Varieties & 0.096 & 0.013 \\
\hline & & Tech-application & 0.148 & 0.020 \\
\hline & & Type product & 0.199 & 0.027 \\
\hline & & Fertilizer & 0.201 & 0.027 \\
\hline & & Pesticides & 0.234 & 0.032 \\
\hline \multirow{4}{*}{ Physical } & \multirow{4}{*}{0.188} & Weather & 0.247 & 0.046 \\
\hline & & Drought & 0.166 & 0.031 \\
\hline & & Flood & 0.295 & 0.055 \\
\hline & & Amount of rain & 0.292 & 0.055 \\
\hline \multirow{4}{*}{ Economic } & \multirow{4}{*}{0.165} & Income & 0.452 & 0.075 \\
\hline & & Cost & 0.076 & 0.013 \\
\hline & & Profit & 0.376 & 0.062 \\
\hline & & Benefit/cost & 0.096 & 0.016 \\
\hline \multirow{7}{*}{ Social } & \multirow{7}{*}{0.347} & Policy & 0.064 & 0.022 \\
\hline & & Labor & 0.155 & 0.054 \\
\hline & & Capital & 0.121 & 0.042 \\
\hline & & Knowledge & 0.147 & 0.051 \\
\hline & & Infrastructure & 0.205 & 0.071 \\
\hline & & Experts & 0.065 & 0.023 \\
\hline & & Scale & 0.243 & 0.084 \\
\hline \multirow{5}{*}{ Environment } & \multirow{5}{*}{0.163} & Soil pollution & 0.126 & 0.020 \\
\hline & & Water pollution & 0.150 & 0.024 \\
\hline & & Salinization & 0.262 & 0.043 \\
\hline & & Acidification & 0.255 & 0.041 \\
\hline & & Disease & 0.208 & 0.034 \\
\hline
\end{tabular}

\subsection{The sub-criteria (C2) about techniques}

Includes the seasonal calendar, seed varieties, techniques, production methods (Schreinemachers and Berger, 2011), methods of using fertilizers and plant protection chemicals (Figure 3) (Ada et al., 1998; Sajesh and Padaria, 2019). The results showed that the pesticide and fertilizer were two important factors in farming techniques (Table 2); These two factors were important due to the resolution of crops disease problems and supply of nutrients under the continuing of local production, which reduces the soil nutrient quality and land availability (Le and Tran, 2013; Nasim et al., 2018). The results also showed that the crops seed varieties factor was less important in agricultural production because most farmers in the area have used and selected pure varieties, and low quality. The results are in agreement with the findings of Ramasubramanian et al. (2014) for the quality seed availability. 


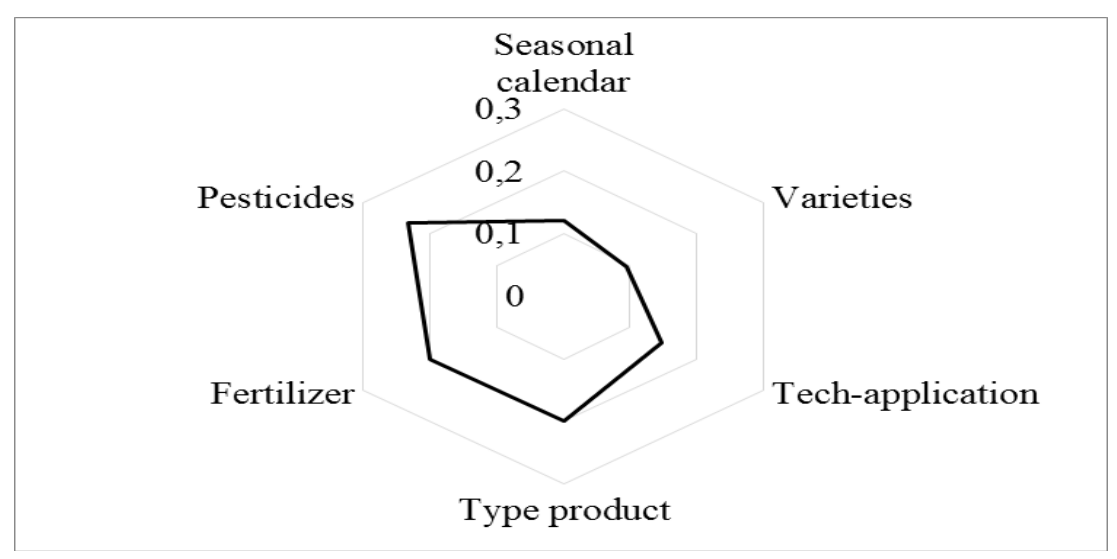

\section{Figure 3: The chart for sub-criteria about techniques}

\subsection{The sub-criteria (C2) about physical}

Properties are such as erratic weather changes, prolonged drought, flooding and rainfall (Figure 4). In the Mekong Delta, drought/flooding have played an important role in agricultural development (Das, 2005). Flooding and rainfall are two factors of high concern (Table 2) because local flooding affects crops; reducing productivity and product quality, and affecting harvest as well. Besides, during the time in the rice field or flowering of fruit trees, the rain causes a drop of the fruit and produces much less fruit, resulting in the low productivity and quality of agricultural products. The factor of the prolonged drought was less concerned because the district has many rivers and canal systems. Therefore irrigation demand is stable and irrigation water supply for the region's crops is adequate.

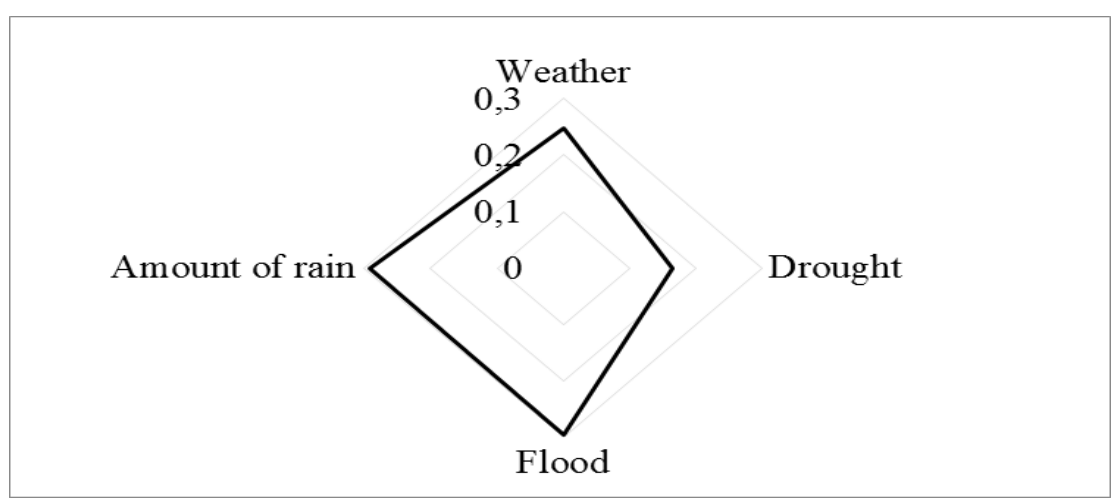

Figure 4: The chart for sub-criteria about physical

\subsection{The sub-criteria (C2) about economic}

Properties determined including the investment costs, model income, production profits, and capital efficiency in agriculture production diversifies (Bowman and Zilberman, 2013.) (Figure 5). In which, income and profit were the two factors that greatly affect agricultural production (Rajendra et al., 2019, Viaggi et al., 2013), followed by capital efficiency and investment costs (Table 2). The results showed that the local economic conditions, the production of the high-income land-use type were an important factor of decisive decision making on agricultural production. The profits were equally important at the same time. When production has brought about profits and high economic efficiency, people are only interested in the investment costs of the production land-use type. 


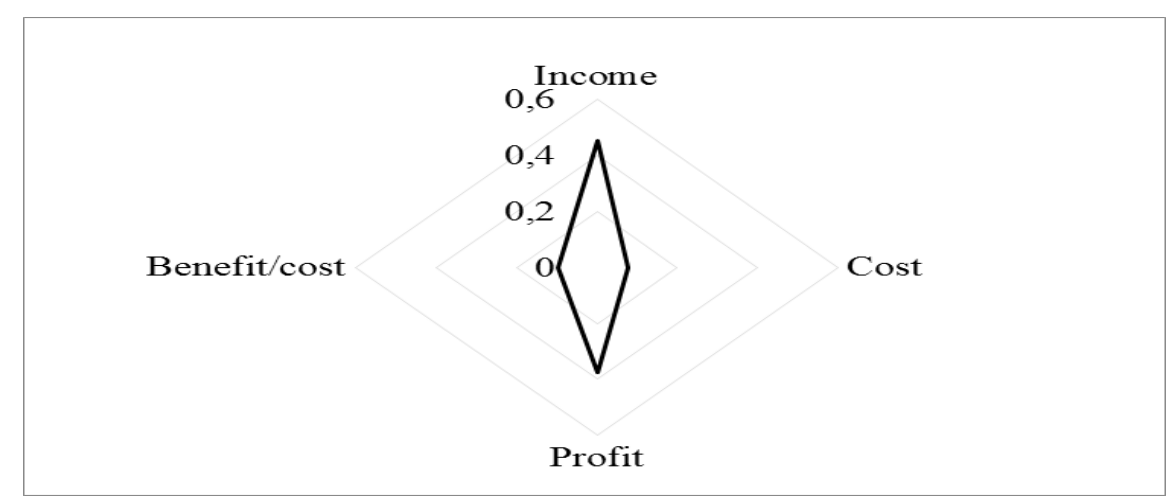

Figure 5: The chart for sub-criteria about economic

\subsection{The sub-criteria (C2) about social}

Affairs affecting agricultural production most in the district was the scale of production, followed by infrastructure, labour sources, people's knowledge, and capital sources (Figure 6). Advisors and supporting policies in agricultural production were the least influential factors (Table 2). According to experts, the policy of supporting local agricultural production was not much and the level of support was low (mainly supporting annual water pumping), the training for farmers on science and technology. There were no policies to support capital, consumption, and chain of link policies. The production scale and infrastructure were social factors highly influenced by small and fragmented production conditions, while the area of raw material products has not been developed, resulting in low product quality and uneven, inadequate irrigation system, inland canals affect the transportation of agricultural products.

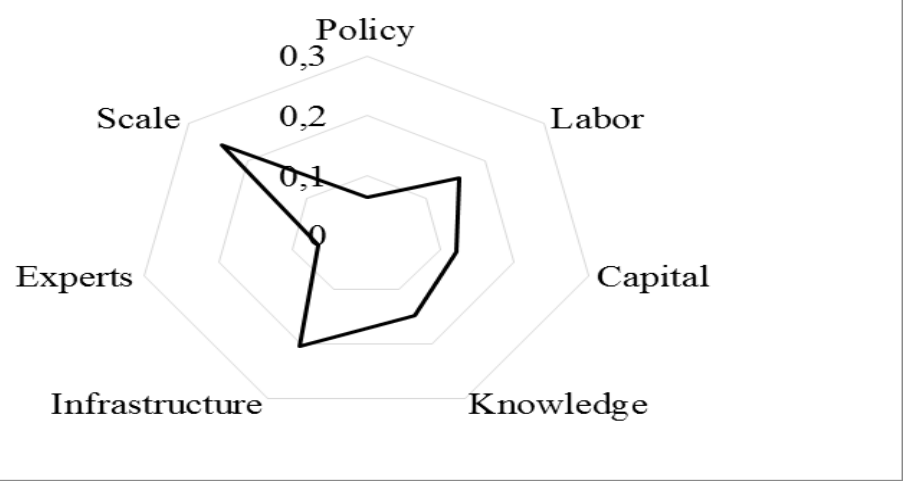

Figure 6: The chart for sub-criteria about social

\subsection{The sub-criteria (C2) about the environmental}

Factors have identified the saline element as the one that was considered to be the most influenced by the salinity element that has a great impact on crops (the plant varieties in the district are grown in freshwater), followed by acidic soils, the increase in disease, water pollution and soil pollution (Table 2, Figure 7) were the factors that have little effect on the agricultural production of the study area. 


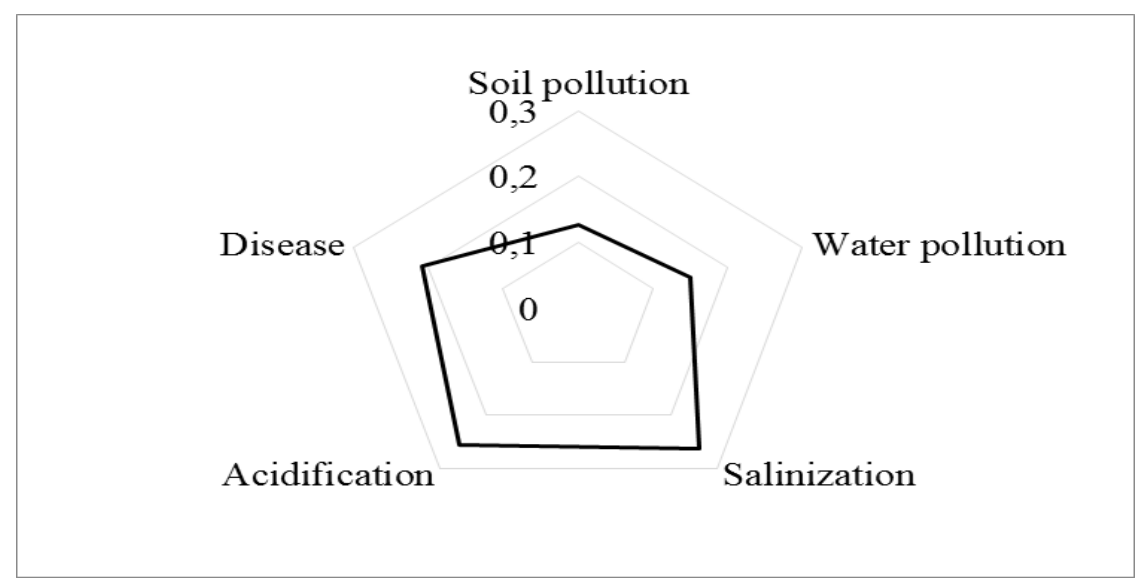

\section{Figure 7: The chart for sub-criteria about the environment}

Therefore, with 26 Sub-criteria $(C 2)$ affecting agricultural production in the district, the economic criteria [total revenue $(0.075)$ and profit $(0.062)$ ] was still the leading decision criteria, followed by infrastructure criteria (0.071), scale (0.084), and criteria of plant varieties (0.013) are of little interest in the cultivation process in the district.

\subsection{The Solutions for sustainable agricultural production in the study area}

Based on the criteria and sub-criteria were determined above, some solutions for sustainable agricultural production:

1) Several scientific and technical measures need to be carried out to limit the use of inorganic fertilizers and plant protection chemicals, and to raise the awareness for people to use organic matter and to apply high-tech agriculture.

2) The local managers also need to focus on repairing, upgrading and constructing a closed dyke system, and irrigation systems to limit the impact of flooding in the rainy season;

3) The policymakers need to develop the strategies to manage the agricultural materials appropriately to ensure quality, as well as to reduce the production costs. At the same time, it is necessary to build a system of linking offsets of agricultural products to ensure outputs for agricultural products.

4) It is necessary to recommend the concentrated production areas towards uniform product quality, as well as to support policies on land to expand the farming scale to meet the supply of raw materials.

5) The training on scientific and technical measures for farmers to limit the use of inorganic fertilizers that adversely affect soil resources such as soil acidity and salinity formation in the production process.

\section{CONCLUSION}

Based on the study results showed that agricultural production is very complex with many factors influence and interact with each other. The study concluded that of the five $(05)$ criteria $(\mathrm{C} 1)$, the social criteria are most interested in agricultural production. In which, twenty-six (26) additional sub-criteria (C2) were identified affecting the agricultural production of the study district. The criteria of income, infrastructure and profit were the main influencing criteria, and the policies to support agriculture and plant varieties were the criteria that have less impact on production. This factors supported the current policymakers to promote the production status of farmers and will prove as a benefit for district agriculture in the coming future. The AHP was a useful tool to assist the determination of the current limitation of criteria in agricultural production and proposed 
solutions have been developed to improve the livelihood ability in the future for a larger extent. The research results were the basis for further studies on land use and climate change, it should be consulted by managers with necessary and effective orientations to cope with issues change contribute to sustainable agricultural development strategy.

Funding: This study is funded in part by the Mekong Delta Rice Research Institute Project BĐKH.42/1620, supported by the Ministry of Natural Resources and Environment. In part by the Can Tho University Improvement Project VN14-P6, (supported by a Japanese ODA loan), and Ministry of Education support for the annual study.

Competing Interests: The authors declared that they have no conflict of interests.

Contributors/Acknowledgement: All authors participated equally in designing and estimation of current research.

Views and opinions expressed in this study are the views and opinions of the authors, Asian Journal of Agriculture and Rural Development shall not be responsible or answerable for any loss, damage or liability, etc. caused in relation to/arising out of the use of the content.

\section{References}

Ada, R. L., Kamta, Y., Prasad, V., Gangwar, K. S., \& Dwivedi, B. S. (1998). Cropping systems and resource-use efficiency. Indian Journal of Agricultural Sciences, 68(8), 548-558.

Ali, A. B., Hossein, A., Milad, D. P., Philippe, L., \& Mostafa, Q. (2019). Determining key agricultural strategic factors using AHP-MICMAC. Sustainability, 11(14), 39-47. doi:10.3390/su11143947.

Bowman, M. S., \& Zilberman, D. (2013). Economic factors affecting diversified farming systems. Ecology and Society, 18(1), 33-46. doi.org/10.5751/ES-05574-180133.

Chiranjit, S., \& Kishore, C. S. (2016). Land suitability evaluation criteria for agricultural crop selection: A review. Agricultural Reviews, 37(2), 125-132. doi: 10.18805/ar.v37i2.10737.

Das, H. P. (2005). Agricultural drought mitigation and management of sustained agricultural development in India. In Natural Disasters and Extreme Events in Agriculture: Impacts and Mitigation, Springer: Berlin/Heidelberg, Germany, 22, 277-303.

Du, L. M. H., Phan, C. N., \& Le, Q. T. (2018). Factors affecting the land potential for developing durian in Cai Be district, Tien Giang province. Journal of Vietnam Soil Science, 53, 107-112.

Gloria, T. P., Lippiatt, B. C., \& Cooper, J. (2007). Life cycle impact assessment weights to support environmentally preferable purchasing in the United States. Environmental Science \& Technology, 41(21), 7551-7557. doi: 10.1021/es070750.

Ha, T. T. D., \& Nguyen, T. M. (2016). Influence of catastrophes and epidemics on agricultural production of households in the central highlands. Science \& Technology Development, 19, 19-29.

Jacek, M. (1996). A GIS-based approach to multiple criteria group decision-making. International Journal of Geographical Information Systems, 10(8), 955-971. doi: 10.1080/02693799608902119.

Khoza, T. M., Senyolo, G. M., Mmbengwa, V. M., \& Soundy, P. (2019). Socio-economic factors influencing smallholder farmers' decision to participate in agroprocessing industry in Gauteng province, South Africa. Cogent Social Sciences, 59(1), 1664193. doi.org/10.1080/23311886.2019.1664193.

Le, V. K., \& Tran, B. L. (2013). Soil degradation and conservation. Publishing house. Can Tho University. 128p.

Lu, J., Zhang, G., Ruan, D., \& Wu, F. (2007). Multi-objective group decision making: method, software, and application with fuzzy techniques. World Scientific Publishing, Singapore, Vol 6. Imperial College Press. 408p.

Nasim, A., Sinha, D. K., \& Singh, K. M. (2018). Changes in land use pattern and factors responsible for variations in current fallow land in Bihar, India. Agricultural research communication centre. Indian Journal of Agricultural Research, 52(3), 236-242. doi: 10.18805/IJARe.A-4955. 
Nguyen, D. T., \& Truong, V. T. (2014). Climate change and its impacts on agricultural production in Quy Nhon city, Binh Dinh province. TP. Ho Chi Minh University Journal of Science, 64, 163-171.

Nguyen, H. T., \& Van, P. D. T. (2014). Possible impacts of seawater intrusion and strategies for water management in coastal areas in the Vietnamese Mekong delta in the context of climate change in coastal disasters and climate change in Vietnam. Elsevier Inc. USA.

Nguyen, T. M. H., \& Do, T. K. H. (2015). Solutions to minimize environmental pollution and degradation during agricultural land use in Vietnam. Vietnam Environment Administration Magazine, No 3/2015.

People's Committee of Chau Thanh A district (2017). Report on agricultural production situation in Chau Thanh A district in 2017 and agricultural development plan in 2018. Vietnam

People's Committee of Hau Giang province (2016). The socio-economic development plan of Hau Giang province in 5 years 2016-2020. Vietnam

Phan, C. N., Le Quang Tri, P. T. V., Minh, V. Q., Tam, V. T., \& Thanh, V. V. (2017). Assessment of criterion of high technology for rice and vegetable production at Thoai Son and Chau Phu-An Giang province. Can Tho University Journal of Science, 1, 39-48

Rajendra, H., Bhaskar, B. P., Niranjana, K. V., Kumar, S. C., Ramamurthy, V., Srinivas, S., \& Singh, S. K. (2019). Land evaluation for groundnut (Arachis hypogaea L.) production in Pulivendula tehsil, Kadapa district, Andhra Pradesh, India. Agricultural research communication centre. Legume Research, 42(3), 326-333. doi: 10.18805/LR-3852.

Ramasubramanian, V., Amrender, K., Prabhu, K. V., Bhatia, V. K., \& Ramasundaram, P. (2014). Forecasting technological needs and prioritizing factors in agriculture from a plant breeding and genetics domain perspective: A review. Indian Journal of Agricultural Sciences, 84(3), 311-316.

Saaty, T. L. (1980). The analytic hierarchy process. McGraw Hill. New York.

Saaty, T. L., \& Peniwati, K. (2008). Group decision making: drawing out and reconciling differences. Pittsburgh, PA: RWS Publications.

Sajesh, V. K., \& Padaria, R. N. (2019). Farmers' extension priorities and service quality of extension agencies: evidence from Maharashtra state of India. Indian Journal of Agricultural Sciences, 89(3), 534-539.

Schreinemachers, P., Berger, T. An agent-based simulation model of human-environment interactions in agricultural systems. Environmental Modelling \& Software, 26, 845-859. doi.org/10.1016/j.envsoft.2011.02.004.

Smajgl, A., Toan, T. Q., Nhan, D. K., Ward, J., Trung, N. H., Tri, L. Q., Tri, V. P. D., \& Vu, P. T. (2015). Responding to rising sea-levels in Vietnam's Mekong Delta. Nature Climate Change, 5(2), 167-174. doi: 10.1038/nclimate2469.

Thirumalaivasan, D., Karmegam, \& Venugopal, K. (2003). AHPDRASTIC: software for specific aquifer vulnerability assessment using DRASTIC model and GIS. Environmental Modelling \& Software, 18(7), 645-656.

Viaggi, D., Raggi, M., \& Gomezy, P. S. (2013). Modelling and interpreting the impact of policy and price scenarios on farm-household sustainability: Farming systems vs. result-driven clustering. Environmental Modelling \& Software, 43, 96-108. doi.org/10.1016/j.envsoft.2013.01.014. 